\title{
APPLICATION OF HOPFIELD NEURAL NETWORK FOR DISTRIBUTION NETWORK'S RECONFIGURATION
}

\author{
NGUYEN TUNG LINH $^{1}$, PHAM THUONG CAT ${ }^{2}$ \\ ${ }^{1}$ Electric Power University;linhnt@epu.edu.vn \\ ${ }^{2}$ Institute of Informations and Technology, \\ Vietnam Academy of Science and Technology; ptcat@ioit.ac.vn
}

Tóm tắt. Trong hệ thống điện, tổn thất điện năng của mạng điện phân phối chiếm tỉ lệ lớn. Nhằm mục tiêu giảm hao phí điện năng người ta áp dụng nhiều phương pháp như: cải tạo lưới điện, đặt tụ bù với dung lượng và vị trí thích hợp, vận hành tối ưu hệ thống ... vv. Trong bài báo này đề cập đến một phương pháp khác để làm giảm tổn thất đó là phương pháp tái cấu trúc. Phương pháp tái cấu trúc là phương pháp tìm ra một cấu trúc lưới tối ưu để vận hành mạng điện có tổn thất nhỏ nhất. Việc tái cấu trúc bằng phương pháp cổ điển sẽ đòi hỏi rất nhiều thời gian đối với mạng điện có nhiều nút, và không thích hợp cho việc đáp ứng nhanh. Vì vậy, trong bài báo này đề xuất việc sử dụng mạng noron Hopfield để tìm kiếm cấu trúc tối ưu của lưới phân phối. Phương pháp đề xuất được kiểm chứng trên các dữ liệu lưới điện mẫu của IEEE. Kết quả của phương pháp đề xuất cho kết quả chính xác và đạt được tổn thất mạng điện tối ưu.

Từ khóa. Lưới điện phân phối, mạng Hopfield, tái cấu trúc, tổn thất điện năng.

\begin{abstract}
In power systems, power losses of system distribution networks take large proportion. In order to reduce power waste we have applied a variety of methods such as: improving the grid, setting the capacitor capacity and suitable location, optimizing operating system... etc. This paper refers to a method for reducing such losses which is restructuring method. Reconfiguration method is a method of finding the optimal network reconfiguration to operate the electricity network to the smallest losses. The restructuring of the classical method would require a lot of time on the distribution networks, which have many nodes, and is not suitable for the fast response. So, this paper proposes the use of Hopfield neural network to find the optimal reconfiguration of the distribution network. The method proposed is tested on the data grid form of the IEEE. The result of proposed methods for similar results with other method and optimal function has a minimum.
\end{abstract}

Key words. Distribution network, Hopfield neural network, reconfiguration, power loss.

\section{INTRODUCTION}

The distribution network directly transmitting power to loads in which power is consumed is a partial accounting for a high proportion in the power system of the nation. In the power system, the power looses on the distribution system accounts for a significant proportion. In particular, according to the statistic of the Vietnam Electricity corporation, the power looses accounts for $10-15 \%$ of the total power system generation every year, in which the power 
losses in distribution system accounts for 5-7\% [1]. The cause of power loosing over distribution system consists of many factors such as: many levels of voltages, not a good operating method, complexity of line, different features of loads, and so on... In contrast, the distribution network has characters: close loop design, but open operation. Hence, the solution to of the distribution network reconfiguration problem is to find a contractor with radical operating method, which assures the reduction of power losses in the distribution network and technical demands by which the system operates normally.

The distribution network is constructed with the close - loop configuration, but operates with radical configuration. This means that the distribution network system is divided into many subsystems through changing states of switches. With graph theory, the distribution network system could be represented as a $G(N, B)$ graph where $N$ is a group of nodes which consist of 2 kinds of node: load node and source node and $B$ is a group of branches in the graph $\mathrm{G}[2]$

In the distribution network, the number of loads is increasing in an acceptable limit, while the configuration of the network is constant. Consequently, if the configuration of the network is constant, its power losses would increase. To reduce the power loss, methods will be used such as: compensating capacitors at suitable locations, improving the grid, etc. However, those methods demand much money, but the effect of the loss reduction is low. Therefore, when the number of load increases in acceptable limit, we could use a reconfiguration method to reduce the power losses in the distribution network to a minimum. We have many methods of the reconfiguration of distribution network by which power loss is minimized, for example, classical method. This method is not used in reality, because it has large solution space. It takes much time to look for an optimal configuration.

Recently, artificial methods have been used such as: Heuristic algorithm [4], Genetic algorithm [3], [5], ant algorithm [6] to solve reconfiguration problem of the distribution network. In this paper, we suggest a Hopfield neural network to solve the problem, the result of the problem has been tested in the model electrical grid system of IEEE.

\section{INTRODUCTION OF RECONFIGURATION PROBLEM AND MATHEMATICAL MODEL}

\subsection{Problem:}

The distribution network reconfiguration problem is a discrete nonlinear planning problem with power flow in branches [7] with the aim of finding an optimal operating configuration in order to reduce power loss in distribution network but still ensure technical factors of the electrical network.

\section{Some concepts:}

Configuration: electrical grid is considered as a graph consisting of nodes, branches, weights, etc....

Power Network Reconfiguration: Changing state of switches in order to obtain new operating method.

Power Looses: Power loss of power network is power wasted during transmission and distribution from generation to loads. In power system, power loss depends on the character of the network, transmitting capability of the system, and role of operating person.

Power loss is divided into 2 kinds: Technical losses and non-technical losses.

Technical losses: during transmitting and distributing power from generations to load, one physical process taking place was the current through devices as transformers, conducting 
wire, and other devices inflaming it. This would lead to waste power. In high voltage conducting wire as $110 \mathrm{kV}, 220 \mathrm{kV}, \ldots$ there are power loosest due to corona discharge, underground wire, or dielectric in capacitors, wires with 2 lines, wires with 3 lines in parallel, and so on...

Nontechnical power losses: are losses due to managing process, business power, error of measurement devices, stolen power, etc.

For example: Considering power grid scheme as Fig. 1

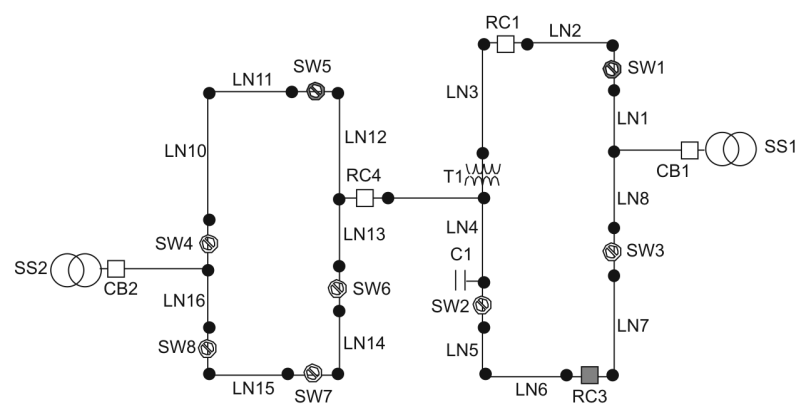

Fig. 1. Considering a scheme of the distribution network.

This is a simple distribution network comprising 2 sources and switches. SW1, SW5, and $\mathrm{RC} 3$ are in open status to assure that power network operates in an open manner. Sections LN2 and LN6 are terminals of network of source SS2. To improve quality of power at the terminal of the network, compensating capacitor is connected between LN3 and LN9. Of course, these devices are all operated in the mode in which parameters are constant during operating time or parameters are varied by remote control or local control. When the above distribution system (Fig. 1) is operated, there could be high losses. However, power losses could be reduced by changing some loads from source SS2 to source SS1, for example, closing RC3 and opening SW2 to bring load sections LN5 and LN6 from SS2 to SS1. Analysis of selection of methods to change states of switches is the content of the distribution network reconfiguration problem (this was proved in papers concerning). In fact, there are hundreds of switches on the distribution network, finding a method to transmit in the best manner among a combination of switches once changing will need a lot of time and must consider technical constraint conditions. As we knew, power network always operates in the condition in which load is not symmetric since we have many kinds of loads and they were not balanced between phases.

Characters and requirements of reconfiguration problem.

Firstly, to solve distribution network reconfiguration problem, the cost function must be constructed. When configuration of power network is changed, there are very many different cost functions, such as cost function minimizing power losses of all systems, cost function assuring qualification of voltage, and so on...

System reconfiguration problem is also the same as other optimal problems such as optimal power distribution calculation problem, calculation to find position, optimal compensity capacity calculation problem... However, requirement calculation amount of reconfiguration problem is high because many variables affect states of switchess and operating conditions such as: distribution network operating in open manner, there is not overload on transformers, wire, switches... and voltage drop at loads being in acceptable bounds.

The model distribution network is a close loop network, but operates in an open manner. This means that operating network must be radically networked. One more issue is that switches must be closed-open in every lap so that power losses of model distribution network 
is minimum. To obtain this, we must have a cost function to find configuration in order to power losses being minimized.

\subsection{Model of reconfiguration problem}

\section{Input:}

- Graph of power network;

- Parameters of devices as wire, transformers, sources, loads, compensating devices, switch, etc.;

- States of switches of power network;

- Power losses of configuration being operated.

\section{Results:}

- New states of switches;

- Power losses satisfying the cost function and constraint conditions.

The cost function:

$$
C=\sum_{i \in j} \frac{P_{i}^{2}+Q_{i}^{2}}{U_{i}^{2}} R_{i}
$$

Function $C$ gets min value.

Constraint conditions: $U_{\min } \leq U_{i} \leq U_{\max }$

$I_{i} \leq I_{\max }$

$N=L_{j}+1$ ( $N$ is a node of distribution network)

Where: $R_{i}$ is the resistance of branches $i-j$.

$P_{i}, Q_{i}$ are active and reactive power at node $i$, respectively.

$U_{\text {max }}, U_{\text {min }}, U_{i}$ are max, min and voltages at node $i$, respectively.

$I_{i}, I_{\max }$ are currents on branches $i$ and maximum current on branches $i$.

$j$ is a group of statues of branches.

Determining the minimum value of the cost function (1) was represented in different methods, such as a classical optimum method, statistic method, artificial intelligent algorithm...

In this paper, the author proposes a use of a Hopfield neural network to determine the optimal states of switches in the scheme.

\section{MODEL OF THE HOPFIELD NETWORK APPLIED TO THE RECONFIGURATION DISTRIBUTION NETWORK PROBLEM}

As we knew, Hopfield network always converges at one balance state which is equivalent with a minimum point of the energy function. Therefore, if the Hopfield network having a configuration which is similar to the power distribution network is established and energy function which is similar to cost function with object to reduce losses is determined, each balance point of Hopfield network is a solution of local optimal reconfiguration problem. This section describes the process establishing the structure of Hopfield networks, which satisfies the necessary constraint conditions and method determining weights which connects nodes of network to solve optimal power distribution network reconfiguration problem. Considering power network scheme below:

The scheme comprises 16 nodes. Solid lines are operating, and dash lines are switching. To assure requirements to operate the power distribution network, object, function, technical requirements of current, voltage, power on branches, loads, after changing operating configuration, the scheme must assure requirements as follows: 


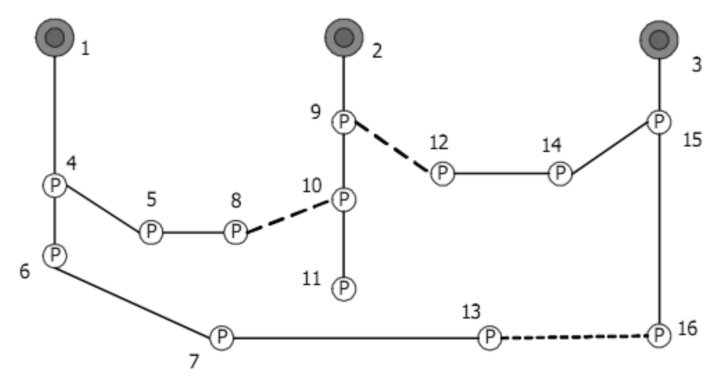

Fig. 2. Example of 16 node distribution network - IEEE.

Each load node is supplied from one branch coming (one load is supplied from only one source).

Cost function reaches minimum value and satisfies constraint conditions (1).

Assuring requirement 1: If power flows from node $i$ to node $j$, then

$$
C_{\mathrm{ij}}= \begin{cases}0 & \text { If branch } i j \text { does not exist. } \\ 1 & \text { If branch } i j \text { exists. }\end{cases}
$$

If one node has a power line flowing from different nodes to it, then we define degree of that node as the number of power line coming that node. For example: In Fig. 3(A), the level

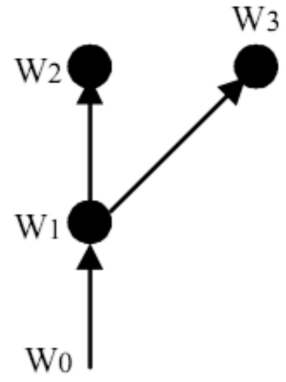

( A)

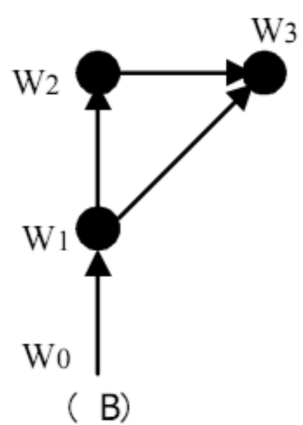

( B)

Fig. 3. Weights of nodes.

number of each node is 1 . The arrows show the direction of each level of the node. In Fig. 3(B), the level number of $W_{3}$ is 2 . The level number of other nodes is 1 .

We can use the neural network with the status of each output neuron corresponding to the nodes of the network power with the output level of the node equal to 1.

To set up the corresponding neural network for power distribution network, we use the method of structuring of Hopfield neural networks by [9] which is arranged in a matrix of size $(N+M+1) \times N$ as presented in Table 1, in which $N+M+1$ is the level number of all nodes and the number of columns refers to the number of all nodes which do not include substations. The $(M+1)$ is the number of substations and $v_{i j}$ is the output of neuron $(i, j)$. In Table 1 , all download button and download button number is $N$ from $W_{-M}$ to $W_{n}$. The distribution substations number is from $W_{0}$ to $\mathrm{W}_{-M}$. In each column of Table 1 , only one element is equal to 1 , the remaining elements are zero. The element with a value of 1 indicates a weighted value of a download button. 
Table 1. Neural network outputs of ensuring condition 1

\begin{tabular}{|c|c|c|c|c|c|}
\hline & $\mathrm{W}_{1}$ & $\mathrm{~W}_{2}$ & $\mathrm{~W}_{3}$ & $\ldots$ & $\mathrm{W}_{n}$ \\
\hline $\mathrm{W}_{-M}$ & 0 & 1 & 0 &. & 0 \\
\hline $\mathrm{W}_{-1}$ & 0 & 0 & 0 & $\ldots$ & 0 \\
\hline $\mathrm{W}_{0}$ & 0 & 0 & 1 & $\ldots$ & 0 \\
\hline $\mathrm{W}_{1}$ & 1 & 0 & 0 & $\ldots$ & 0 \\
\hline $\mathrm{W}_{2}$ & 0 & 0 & 0 & $\ldots$ & 1 \\
\hline$\ldots$ & 0 & 0 & 0 & $\ldots$ & 0 \\
\hline
\end{tabular}

Table 2. Output results of Fig. 3(B) diagram

\begin{tabular}{|c|c|c|c|}
\hline & $\mathrm{W}_{1}$ & $\mathrm{~W}_{2}$ & $\mathrm{~W}_{3}$ \\
\hline $\mathrm{W}_{0}$ & 1 & 0 & 0 \\
\hline $\mathrm{W}_{1}$ & 0 & 1 & 1 \\
\hline $\mathrm{W}_{2}$ & 0 & 0 & 0 \\
\hline $\mathrm{W}_{3}$ & 0 & 0 & 0 \\
\hline
\end{tabular}

For example, the output of the network Hopfileld for restructuring problem for Fig. 3(B) is presented as follows:

Assuring requirement 2: The energy function of the Hopfield network has to ensure network conditions:

$$
\begin{aligned}
C(\mathbf{v})= & \frac{A}{2} \sum_{\alpha=1}^{N}\left(\sum_{i=-M}^{N} v_{i \alpha}-1\right)^{2}+\frac{B}{2} \sum_{i=-M}^{N} \sum_{\alpha=1}^{N} C_{i \alpha} v_{i \alpha}+\frac{G}{2}\left(\sum_{i=-M}^{N} \sum_{\alpha=1}^{N} v_{i \alpha} v_{\alpha i}\right)^{2} \\
& +\frac{H}{2} \sum_{i=-M}^{N} \sum_{\alpha=1}^{N} v_{i \alpha}\left(\frac{\left(R_{i \alpha}+F R(i)\right) *\left(P_{\alpha}^{2}+Q_{\alpha}^{2}\right)}{U_{i}^{2}}+F S R(i, \alpha)\right) \\
& +\frac{K}{2} \sum_{i=-M}^{N} \sum_{\alpha=1}^{N} D_{i \alpha}\left(v_{i \alpha}-1\right)^{2}
\end{aligned}
$$

Where: $A, B, G, K, H$ are the coefficient of self-selected.

$v_{i \alpha}$ is the output of neuron $(i, \alpha)$.

$R_{i \alpha}$ is the resistance of the line $(i, \alpha)$.

$C_{i \alpha}$ is flowing from node $i$ to node $\alpha$ (defined as above).

$P_{\alpha}$ and $Q_{\alpha}$ are the active power and reactive power of node $\alpha$.

$U_{i}$ is the voltage of node $i$.

$D_{i \alpha}$ is 0 or 1 and can be written as follows: $D_{\mathrm{i} \alpha}= \begin{cases}0 & \text { If the branch } i j \text { has a switch } \\ 1 & \text { If the branch } i j \text { has no switch }\end{cases}$

$A$ is the weight of each network node.

$B$ defines branches $i$ - $\alpha$ value existing or not existing.

$G$ is guaranteed that $v_{i \alpha}$ and $v_{\alpha i}$ are not greater than 1 , which means the way of power flows from $(i \rightarrow \alpha)$ and vice versa $(i \leftarrow \alpha)$. Thus, power can flow in one direction.

$H$ is the objective function reducing power loss of distribution network.

$K$ defines the existence of a switch on branches $i \alpha$.

To determine the link between the weights of the neural network, we choose the energy function of the system as follows:

$$
E=-\frac{1}{2} \sum_{i} \sum_{\alpha} \sum_{j} \sum_{\beta} w_{i \alpha, j \beta} v_{i \alpha} v_{j \beta},
$$

where: $w_{i \alpha, j \beta}$ is the weight between two neurons $v_{i \alpha}$ and $v_{j \beta}$. 


$$
\begin{aligned}
& C(\mathbf{v})=\frac{A}{2} \sum_{\alpha=1}^{N}\left(\sum_{i=-M}^{N} \sum_{j=-M}^{N} v_{i \alpha} v_{j \alpha}-2 \sum_{i=-M}^{N} v_{i \alpha}+1\right) \\
& +\frac{B}{2} \sum_{i=-M}^{N} \sum_{\alpha=1}^{N} \sum_{j=-M}^{N} \sum_{\beta=1}^{N} C_{i \alpha} \delta_{i j} \delta_{\alpha \beta} v_{i \alpha} v_{j \beta}+\frac{G}{2} \sum_{i=-M}^{N} \sum_{\alpha=1}^{N} \sum_{j=-M}^{N} \sum_{\beta=1}^{N} v_{\alpha i} v_{\beta j} v_{i \alpha} v_{j \beta} \\
& \quad+\frac{H}{2} \sum_{i=-M}^{N} \sum_{\alpha=1}^{N} \sum_{j=-M}^{N} \sum_{\beta=1}^{N} \delta_{i j} \delta_{\alpha \beta}\left(\frac{\left(R_{i \alpha}+F R(i)\right) *\left(P_{\alpha}^{2}+Q_{\alpha}^{2}\right)}{U_{i}^{2}}+F S R(i, \alpha)\right) v_{i \alpha} v_{j \beta} \\
& \quad+\frac{K}{2} \sum_{i=-M}^{N} \sum_{\alpha=1}^{N} D_{i \alpha}\left(v_{i \alpha}^{2}-2 v_{i \alpha}+1\right)
\end{aligned}
$$

Because $v_{i \alpha} \in\{0,1\}$ so $v_{i \alpha}=v_{i \alpha}^{2}$ so

Where: $\delta_{i j}= \begin{cases}0 & i \neq j \\ 1 & i=j\end{cases}$

Since the constants in the formula (4) do not affect the position of the minimum point of the objective function, so they are ignored.

$$
\begin{aligned}
& C(\mathbf{v})=\frac{A}{2} \sum_{\alpha=1}^{N} \sum_{i=-M}^{N} \sum_{\beta=1}^{N} \sum_{j=-M}^{N} \delta_{\alpha \beta} v_{i \alpha} v_{j \beta}-A \sum_{\alpha=1}^{N} \sum_{i=-M}^{N} \sum_{\beta=1}^{N} \sum_{j=-M}^{N} \delta_{\alpha \beta} \delta_{i j} v_{i \alpha} v_{j \beta} \\
& +\frac{B}{2} \sum_{i=-M}^{N} \sum_{\alpha=1}^{N} \sum_{j=-M}^{N} \sum_{\beta=1}^{N} C_{i \alpha} \delta_{i j} \delta_{\alpha \beta} v_{i \alpha} v_{j \beta}+\frac{G}{2} \sum_{i=-M}^{N} \sum_{\alpha=1}^{N} \sum_{j=-M}^{N} \sum_{\beta=1}^{N} v_{\alpha i} v_{\beta j} v_{i \alpha} v_{j \beta} \\
& +\frac{H}{2} \sum_{i=-M}^{N} \sum_{\alpha=1}^{N} \sum_{j=-M}^{N} \sum_{\beta=1}^{N} \delta_{i j} \delta_{\alpha \beta}\left(\frac{\left(R_{i \alpha}+F R(i)\right) *\left(P_{\alpha}^{2}+Q_{\alpha}^{2}\right)}{U_{i}^{2}}+F S R(i, \alpha)\right) v_{i \alpha} v_{j \beta} \\
& -\frac{K}{2} \sum_{i=-M}^{N} \sum_{\alpha=1}^{N} \sum_{j=-M}^{N} \sum_{\beta=1}^{N} D_{i \alpha} \delta_{i j} \delta_{\alpha \beta} v_{i \alpha} v_{j \beta}
\end{aligned}
$$

By applying the Hopfield nature of the network [10], comparing between (3) and (5) we determine the weighted link between two neurons $v_{i \alpha}$ and $v_{j \beta}$ as follows:

$$
\begin{aligned}
w_{i \alpha, j \beta}= & -A \delta_{\alpha \beta}\left(1-2 \delta_{i j}\right)-B C_{i \alpha} \delta_{\alpha \beta} \delta_{i j}-G v_{\alpha i} v_{\beta j} \\
& -H \delta_{i j} \delta_{\alpha \beta}\left(\frac{\left(R_{i \alpha}+F R(i)\right) *\left(P_{\alpha}^{2}+Q_{\alpha}^{2}\right)}{U_{i}^{2}}+F S R(i, \alpha)\right)+K D_{i \alpha} \delta_{\alpha \beta} \delta_{i j}
\end{aligned}
$$

and $\theta_{i}=2 . A \sum_{i=1}^{n} a_{i \alpha}-B$.

The method of determining the parameters $F R(i)$ and $F S R(i, \alpha)$ :

$F R(i)$ is the total resistance of the branches supplying the line to the node $i$.

$F S R(i, \alpha)$ is the power loss, increases when node $\alpha$ is added to the distribution network.

The $F R(i)$ and $F S R(i, \alpha)$ are calculated by considering each node recursively added to the system to ensure that the grid is radial and the load is supplied from a common source. 

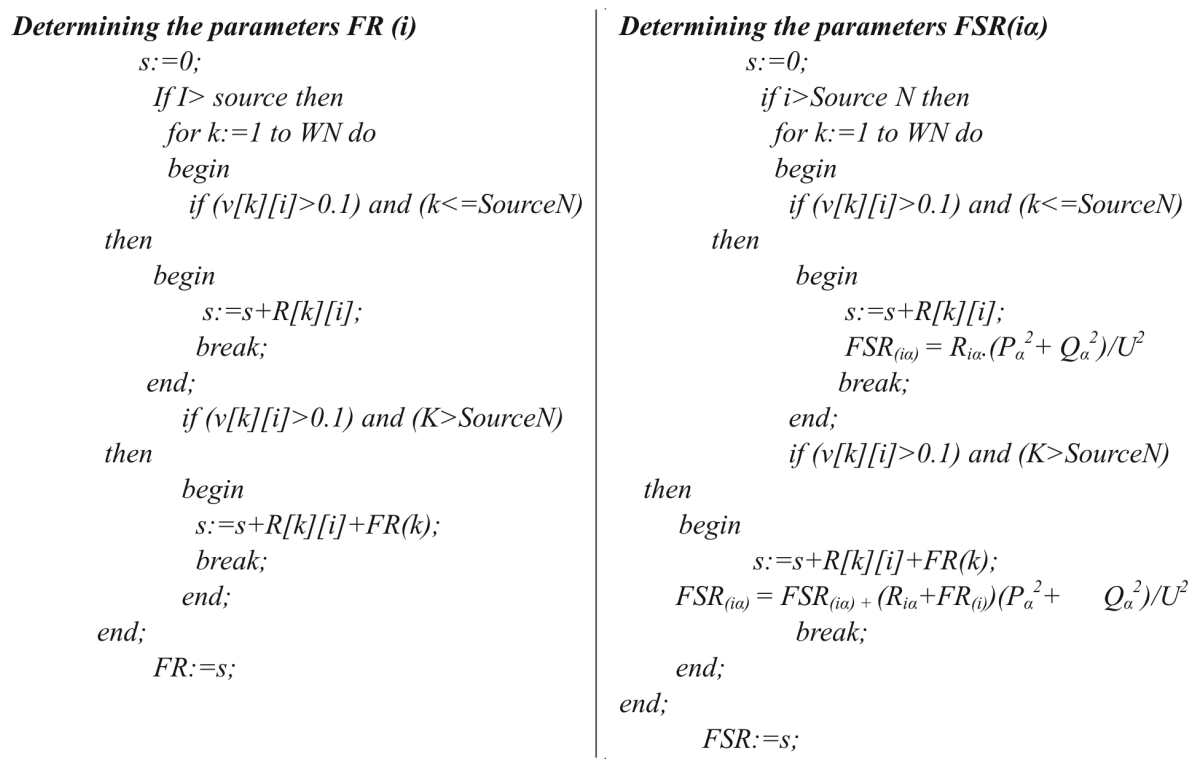

Building Hopfield neural network applied to the reconfiguration analysis of Hopfield neural network consists of $N$ nodes:

\begin{tabular}{|c|c|c|c|c|}
\hline & $\mathrm{W}_{1}$ & $\mathrm{~W}_{2}$ & $\ldots$ & $\mathrm{W}_{\mathrm{N}}$ \\
\hline $\mathrm{W}_{-\mathrm{M}}$ & $v_{-\mathrm{Ml}}$ & $v_{-\mathrm{M} 2}$ & $\ldots$ & $v_{-\mathrm{MN}}$ \\
\hline$\ldots$ & $\ldots$ & $\ldots$ & $\ldots$ & $\ldots$ \\
\hline $\mathrm{W}_{-1}$ & $v_{-11}$ & $v_{-12}$ & $\ldots$ & $v_{-1 \mathrm{~N}}$ \\
\hline $\mathrm{W}_{0}$ & $\mathrm{v}_{01}$ & $v_{02}$ & $\ldots$ & $v_{0 \mathrm{~N}}$ \\
\hline $\mathrm{W}_{1}$ & $v_{11}$ & $v_{12}$ & $\ldots$ & $v_{1 \mathrm{~N}}$ \\
\hline $\mathrm{W}_{2}$ & $v_{21}$ & $\mathrm{v}_{22}$ & $\ldots$ & $\mathrm{v}_{2 \mathrm{~N}}$ \\
\hline$\ldots$ & $\cdots$ & $\ldots$ & $\ldots$ & $\ldots$ \\
\hline $\mathrm{W}_{\mathrm{N}}$ & $v_{\mathrm{N} 1}$ & $v_{2 \mathrm{~N}}$ & $\ldots$ & $v_{\mathrm{NN}}$ \\
\hline
\end{tabular}

Matrix of the Hopfield network$$
\text { Matrix of the Hopfield network }
$$

$$
\text { Input }=\left[\begin{array}{l}
v_{01} \\
v_{02} \\
\cdots \\
v_{0 n} \\
v_{-11} \\
v_{-12} \\
\cdots \\
v_{-m 1} \\
v_{-m 2} \\
\cdots \\
v_{-m n}
\end{array}\right]
$$

Hopfield network: Two-way arrows describe relations between nodes $i-\alpha$ and $\alpha-i$

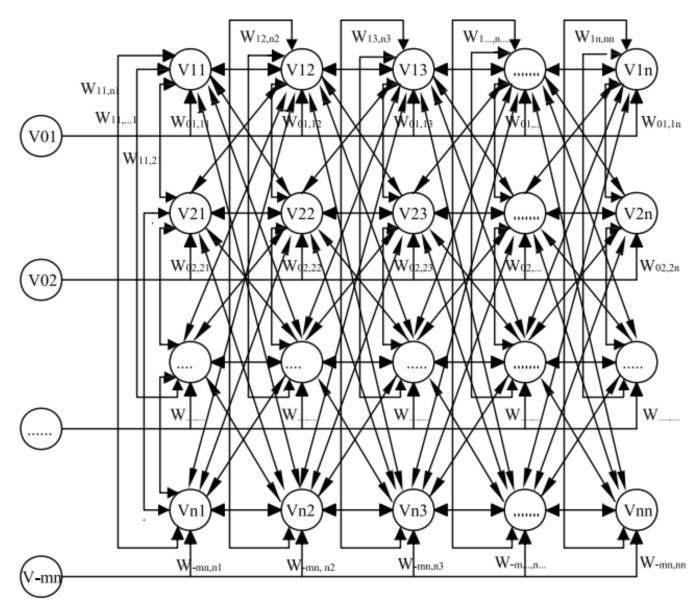


Weight Matrix $=\left[\mathrm{w}_{i \alpha, j \beta}\right]$ in which $\alpha, \beta=1 \ldots N ; i, j=-M, N$

According to [10], we determine the values of output variables of the Hopfield neural network:

$$
v_{\mathrm{i} \alpha}=f\left(a_{i \alpha}\right)=\frac{1}{2}\left(1+\tanh \left(k a_{i \alpha}\right)\right) \text { and } a_{i \alpha}=\sum_{j=-M}^{N} \sum_{\beta=1}^{N} \mathrm{w}_{\mathrm{i} \alpha, \mathrm{j} \beta} \cdot v_{i \beta}
$$

\section{TEST EXAMPLE}

Considering the example network consisting of 16 nodes of the IEEE [8], network diagram consists of 16 nodes (including 3 sources, 13 load nodes and 3 radial networks). Network diagram is shown as Fig. 5

Table 3. Data of network diagram Fig. 5

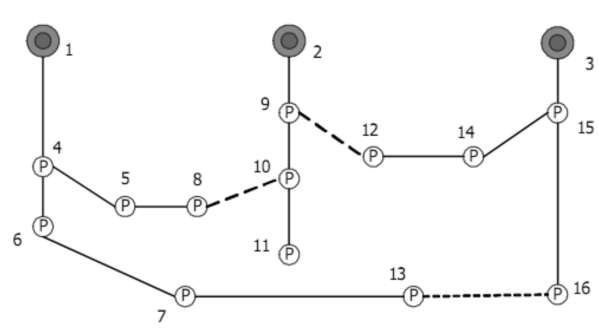

\begin{tabular}{|c|c|c|c|c|}
\hline Branches i-j & $\mathrm{R}(\mathrm{pu})$ & $\mathrm{X}(\mathrm{pu})$ & $\mathrm{P}(\mathrm{MW})$ & $\mathrm{Q}($ MVAr $)$ \\
\hline $1-4$ & 0.075 & 0.1 & 2.0 & 1.5 \\
\hline $4-5$ & 0.08 & 0.11 & 3.0 & 1.5 \\
\hline $4-6$ & 0.09 & 0.18 & 2.0 & 0.8 \\
\hline $6-7$ & 0.04 & 0.04 & 1.5 & 1.2 \\
\hline $2-8$ & 0.11 & 0.11 & 4.0 & 2.7 \\
\hline $8-9$ & 0.08 & 0.11 & 5.0 & 3.0 \\
\hline $8-1$ & 0.11 & 0.11 & 1.0 & 0.9 \\
\hline $9-11$ & 0.11 & 0.11 & 0.6 & 0.1 \\
\hline $9-12$ & 0.08 & 0.11 & 4.5 & 2.0 \\
\hline $3-13$ & 0.11 & 0.11 & 1.0 & 0.9 \\
\hline $13-14$ & 0.09 & 0.12 & 1.0 & 0.7 \\
\hline $13-15$ & 0.08 & 0.11 & 1.0 & 0.9 \\
\hline $15-16$ & 0.04 & 0.04 & 2.1 & 1.0 \\
\hline $5-11$ & 0.04 & 0.04 & & \\
\hline $10-14$ & 0.04 & 0.04 & & \\
\hline $7-16$ & 0.09 & 0.12 & & \\
\hline
\end{tabular}

Using Matlab to build a Hopfield network diagram applied to the problem of restructuring the electricity distribution network gives the convergence results, and new structures after computing the objective function (loss of power on the grid) are minimal. Instilling the input values for the Hopfield network.

The values $A, B, G, H, K$ and $k$ coefficient of the output function of neurons are selected as follows

$A=30 ; \%$ Declare Function Cost coefficient values

$B=20 ; \%$ Declare Function Cost coefficient values

$G=30 ; \%$ Declare Function Cost coefficient values

$H=10 ; \%$ Declare Function Cost coefficient value

$K=30 ; \%$ Declare Function Cost coefficient values

$k=1 \mathrm{E} 6 ; \%$ Declare extremely large values

$Z=100 \%$ of the loop

$R=1 \mathrm{E} 6$ if $i-j$ the button is not connected

The value of the energy function in the configuration:

At the reconfiguration beginning: 837,73; 
Hopfield network inputs in Fig. 5 diagram are as follows:

$$
\text { Input }=\left[\begin{array}{l}
v_{01} \\
v_{02} \\
\cdots \\
v_{013} \\
v_{-11} \\
v_{-12} \\
\cdots \\
v_{-31} \\
v_{-32} \\
\cdots \\
v_{-313}
\end{array}\right]
$$

Matrix of switch status before reconfiguration

\begin{tabular}{|l|l|l|l|l|l|l|l|l|l|l|l|l|l|l|l|}
\hline 0 & 0 & 0 & 1 & 0 & 0 & 0 & 0 & 0 & 0 & 0 & 0 & 0 & 0 & 0 & 0 \\
\hline 0 & 0 & 0 & 0 & 0 & 0 & 0 & 0 & 1 & 0 & 0 & 0 & 0 & 0 & 0 & 0 \\
\hline 0 & 0 & 0 & 0 & 0 & 0 & 0 & 0 & 0 & 0 & 0 & 0 & 0 & 0 & 1 & 0 \\
\hline 0 & 0 & 0 & 0 & 1 & 1 & 0 & 0 & 0 & 0 & 0 & 0 & 0 & 0 & 0 & 0 \\
\hline 0 & 0 & 0 & 0 & 0 & 0 & 0 & 1 & 0 & 0 & 0 & 0 & 0 & 0 & 0 & 0 \\
\hline 0 & 0 & 0 & 0 & 0 & 0 & 0 & 0 & 0 & 0 & 0 & 0 & 0 & 0 & 0 & 0 \\
\hline 0 & 0 & 0 & 0 & 0 & 0 & 0 & 0 & 0 & 0 & 0 & 0 & 1 & 0 & 0 & 0 \\
\hline 0 & 0 & 0 & 0 & 0 & 0 & 0 & 0 & 0 & 0 & 0 & 0 & 0 & 0 & 0 & 0 \\
\hline 0 & 0 & 0 & 0 & 0 & 0 & 0 & 0 & 0 & 1 & 0 & 0 & 0 & 0 & 0 & 0 \\
\hline 0 & 0 & 0 & 0 & 0 & 0 & 0 & 0 & 0 & 0 & 1 & 0 & 0 & 0 & 0 & 0 \\
\hline 0 & 0 & 0 & 0 & 0 & 0 & 0 & 0 & 0 & 0 & 0 & 0 & 0 & 0 & 0 & 0 \\
\hline 0 & 0 & 0 & 0 & 0 & 0 & 0 & 0 & 0 & 0 & 0 & 0 & 0 & 0 & 0 & 0 \\
\hline 0 & 0 & 0 & 0 & 0 & 0 & 1 & 0 & 0 & 0 & 0 & 0 & 0 & 0 & 0 & 0 \\
\hline 0 & 0 & 0 & 0 & 0 & 0 & 0 & 0 & 0 & 0 & 0 & 1 & 0 & 0 & 0 & 0 \\
\hline 0 & 0 & 0 & 0 & 0 & 0 & 0 & 0 & 0 & 0 & 0 & 0 & 0 & 1 & 0 & 1 \\
\hline 0 & 0 & 0 & 0 & 0 & 0 & 0 & 0 & 0 & 0 & 0 & 0 & 0 & 0 & 0 & 0 \\
\hline
\end{tabular}

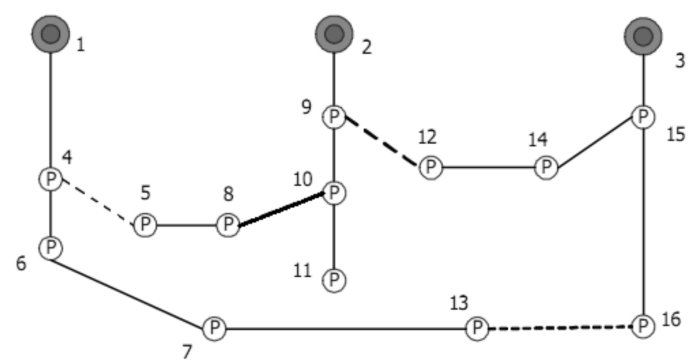

Fig. 6. $1^{\text {st }}$ simulation results

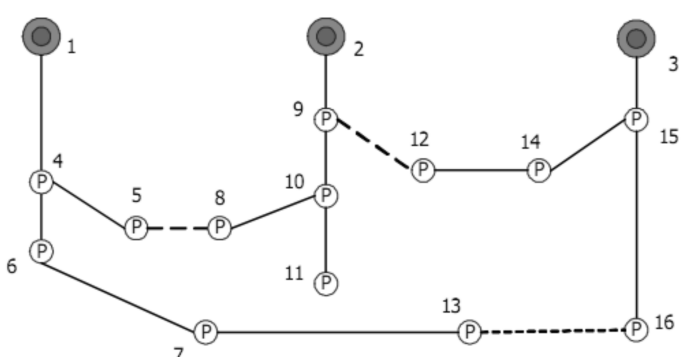

Fig. 7. $2^{\text {nd }}{ }^{7}$ simulation results

Implementation of the $1^{\text {st }}$ optimal simulation Performing the $2^{\text {nd }}$ simulation, optimization time 1 we obtain result for the $1^{\text {st }}$ energy function being 834,073 (Fig. 6). we have the value of the $2^{\text {nd }}$ energy function being 769,863 (Fig. 7 ).

Performing the $3^{\text {rd }}$ time of the optimal simulation, we have the value of the $3^{\text {rd }}$ energy function being 785,402 (Fig. 8).

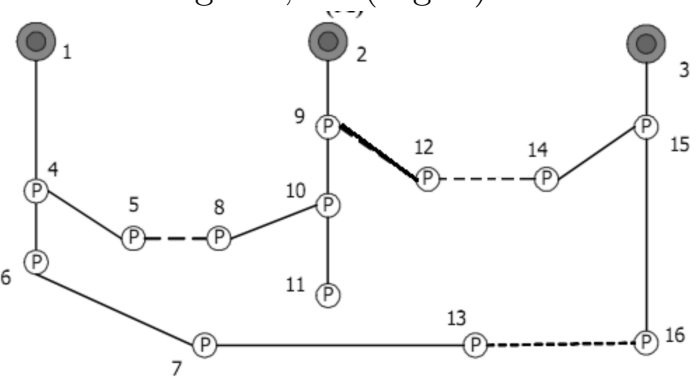

Fig. 8. $3^{\text {rd }}$ simulation results.

Value in the $3^{\text {rd }}$ energy function being 785,402 
The matrix of the lock status (switch) after reconfiguring

\begin{tabular}{|l|l|l|l|l|l|l|l|l|l|l|l|l|l|l|l|}
\hline 0 & 0 & 0 & 1 & 0 & 0 & 0 & 0 & 0 & 0 & 0 & 0 & 0 & 0 & 0 & 0 \\
\hline 0 & 0 & 0 & 0 & 0 & 0 & 0 & 0 & 1 & 0 & 0 & 0 & 0 & 0 & 0 & 0 \\
\hline 0 & 0 & 0 & 0 & 0 & 0 & 0 & 0 & 0 & 0 & 0 & 0 & 0 & 0 & 0 & 1 \\
\hline 0 & 0 & 0 & 0 & 1 & 1 & 0 & 0 & 0 & 0 & 0 & 0 & 0 & 0 & 0 & 0 \\
\hline 0 & 0 & 0 & 0 & 0 & 0 & 0 & 0 & 0 & 0 & 0 & 0 & 0 & 0 & 0 & \\
\hline 0 & 0 & 0 & 0 & 0 & 0 & 1 & 0 & 0 & 0 & 0 & 0 & 0 & 0 & 0 & 0 \\
\hline 0 & 0 & 0 & 0 & 0 & 0 & 0 & 0 & 0 & 0 & 0 & 0 & 1 & 0 & 0 & 0 \\
\hline 0 & 0 & 0 & 0 & 0 & 0 & 0 & 0 & 0 & 0 & 0 & 0 & 0 & 0 & 0 & \\
\hline 0 & 0 & 0 & 0 & 0 & 0 & 0 & 0 & 0 & 1 & 0 & 0 & 0 & 0 & 0 & 0 \\
\hline 0 & 0 & 0 & 0 & 0 & 0 & 0 & 1 & 0 & 0 & 1 & 0 & 0 & 0 & 0 & 0 \\
\hline 0 & 0 & 0 & 0 & 0 & 0 & 0 & 0 & 0 & 0 & 0 & 0 & 0 & 0 & 0 & \\
\hline 0 & 0 & 0 & 0 & 0 & 0 & 0 & 0 & 0 & 0 & 0 & 0 & 0 & 0 & 1 & 0 \\
\hline 0 & 0 & 0 & 0 & 0 & 0 & 0 & 0 & 0 & 0 & 0 & 0 & 0 & 0 & 0 & \\
\hline 0 & 0 & 0 & 0 & 0 & 0 & 0 & 0 & 0 & 0 & 0 & 1 & 0 & 0 & 0 & 0 \\
\hline 0 & 0 & 0 & 0 & 0 & 0 & 0 & 0 & 0 & 0 & 0 & 0 & 0 & 1 & 0 & 1 \\
\hline 0 & 0 & 0 & 0 & 0 & 0 & 0 & 0 & 0 & 0 & 0 & 0 & 0 & 0 & 0 & 0 \\
\hline
\end{tabular}

Since Hopfield networks always converge at a local equilibrium, despite of the fact that the network comes from different initial states, it always converges at a nearby minimal point. After performing simulations on grid of 16 nodes, 3 sources, 3 loops and performing optimum operation for 3 times, we recognize that energy function values are respectively 834,07; 769,863; 785,402 . Therefore, the objective function value achieved in the 2 nd operation has structure meeting requirements. The rate of power loss reduction compared with the initial configuration, operation is $\sim 8.1 \%$.

\section{CONCLUSION}

In this paper, the authors have proposed methods to determine minimal values for the restructuring problem by applying the properties of Hopfield networks. Then we built Hopfiled networks for the restructuring problem. Research results of the paper has overcome the divergence properties in the paper [7] and results of simulation for Matlab are the same as research results [9].

The results ensured that the objective function gave minimal value and satisfied technical constraints to the problem of distribution grid operator. Applying neural networks to the problem of restructuring minimizes computational times and fast convergence. However, the convergence of the Hopfiled network optimization has showed local properties of the energy function. So to achieve a global optimization solution, some additional algorithms such as simulated annealing algorithm (SA), Boltzmann networks or Gaussian network need applying. These studies will be our next research phase.

\section{REFERENCES}

[1] Vietnam Electricity Group (EVN), Plan Final Report, 2012. 
[2] Helon David de Macêdo Braz and Benemar Alencar de Souza, Distribution Network Reconfiguration Using Genetic Algorithms With Sequential Encoding: Subtractive and Additive Approaches IEEE Transactions on Power System 26(2) (2011), 356 - 362.

[3] J. Z. Zhu, Optimal Reconfiguration of distribution network using the refined genetic algorithm, ELSEVIER Elect. Power Syst. Res. 62 (2002), 37-42.

[4] Chang, H.-C. and Ch.-Ch. Kuo, Network reconfiguration in distribution systems using simulated annealing, Electric Power Systems Research 29 (1994), 227-238.

[5] F. Batrinu, E. Carpaneto, and G. Chicco, A Novel Particle Swarm Method for Distribution System Optimal Reconfiguration, Proc. 2005 IEEE Russia PowerTech, Jun., (2005), 27-30.

[6] M.A. Ghorbani, S.H. Hosseinian, and B. Vahidi, Application of ant colony system algorithm to distribution networks reconfiguration for loss reduction, Optimization of Electrical and Electronic Equipment, 2008. OPTIM 2008. 11th International Conference, May 22-24, 2008, 269-273.

[7] Demck Bouchard, Aziz Chikhani, V.L John, M.M.A. Salama, Applications of Hopfield neural networks to distribution feeder reconfiguration, Proceedings of the Second International Forum on Applications of Neural Networks to Power Systems, ANNPS 93, 1993, 331-316.

[8] M. E. Baran and F. F. Wu, Network Reconfiguration in Distribution Systems for Loss Reduction and Load Balancing, IEEE Trans. Power Del. 4(2) (1989), 1401-1407.

[9] Weixin Gao, Nam Tang, Xiangyang Mu, A distribution network reconfiguration algorithm based on Hopfield neural network, IEEE Proceedings of Fourth International Conference on Natural Computation, May - 2008, 9-13.

[10] Uğur Halici, Artificial neural network, EE543 Lecture Notes, chapter 3, 4, 2004.

Received on February 09, 2014

Revised on May 21, 2014 